provided by Xigen, SA. We thank Catherine Centeno for assistance, Professor $P$ Davis for kindly providing us the specific anti-P-APP antibody, and JD Baggott for revising the manuscript.

\author{
A Colombo ${ }^{1}, M$ Repici ${ }^{2}, M$ Pesaresi $^{1}, S$ Santambrogio ${ }^{1}$, \\ G Forloni ${ }^{1}$ and $T$ Borsello ${ }^{\star, 1,2}$ \\ ${ }^{1}$ Biol. Neurodeg. Disorders Lab, Istituto di Ricerche Farmacologiche 'Mario \\ Negri', Via Eritrea, Milano, Italy and \\ 2 Département de Biologie cellulaire et de Morphologie, Université de Lausanne, \\ Switzerland \\ * Corresponding author: T Borsello, Biol. Neurodeg. Disorders Lab, Istituto di \\ ricerche Farmacologiche, 'Mario Negri', Via Eritrea 62, Milano 20157, Italy. \\ Tel: + 390239014 469; Fax: + 3902354 6277; \\ E-mail: borsello@marionegri.it and \\ Départment de Biologie Cellulaire et de Morphologie, Université de Lausanne, \\ CH-1005, Switzerland. Tel: + 4121692 5277; Fax: + 4121692 5105; \\ E-mail: Tiziana.Borsello@unil.ch \\ 1. Hedera P, Turner RS. Neurol Clin 2002; 20: 779-808, vii. \\ 2. Selkoe DJ. Physiol Rev 2001; 81: 741-766.
}

3. Kalback W, Watson MD, Kokjohn TA, Kuo YM, Weiss N, Luehrs DC et al. Biochemistry 2002; 41: 922-928.

4. Brown MS, Ye J, Rawson RB, Goldstein JL. Cell 2000; 100: 391-398.

5. Stokin GB, Lillo C, Falzone TL, Brusch RG, Rockenstein E, Mount SL et al. Science 2005; 307: 1282-1288.

6. LaFerla FM. Nat Rev Neurosci 2002; 3: 862-872.

7. Takeda K, Araki W, Akiyama H, Tabira T. Faseb J 2004; 18: 1755-1757.

8. Taru H, Yoshikawa K, Suzuki T. FEBS Lett 2004; 567: 248-252.

9. Taru H, Kirino Y, Suzuki T. J Biol Chem 2002; 277: 27567-27574.

10. Whitmarsh AJ, Kuan CY, Kennedy NJ, Kelkar N, Haydar TF, Mordes JP et al. Genes Dev 2001; 15: 2421-2432.

11. Kogel D, Schomburg R, Copanaki E, Prehn JH. Cell Death Differ 2005; 12: 1-9.

12. Bonny C, Oberson A, Negri S, Sauser C, Schorderet DF. Diabetes 2001; 50: $77-82$.

13. Flood F, Murphy S, Cowburn RF, Lannfelt L, Walker B, Johnston JA. Biochem J 2005; 385 (Part 2): 545-550.

14. Suzuki T, Oishi M, Marshak DR, Czernik AJ, Nairn AC, Greengard P. EMBO J 1994; 13: 1114-1122.

15. Ramelot TA, Nicholson LK. J Mol Biol 2001; 307: 871-884.

16. Lee MS, Kao SC, Lemere CA, Xia W, Tseng HC, Zhou Y et al. J Cell Biol 2003; 163 : 83-95.

17. Zhu X, Raina AK, Rottkamp CA, Aliev G, Perry G, Boux H et al. J Neurochem 2001; 76: 435-441.

18. Muresan Z, Muresan V. C J Cell Biol 2005; 171: 615-625.

\title{
Calreticulin exposure is required for the immunogenicity of $\gamma$-irradiation and UVC light-induced apoptosis
}

\author{
Cell Death and Differentiation (2007) 14, 1848-1850; doi:10.1038/sj.cdd.4402201; published online 27 July 2007
}

\author{
Dear Editor,
}

It is commonly assumed that the only goal of anticancer chemotherapy, like antimicrobial antibiotic therapy, is to eradicate by direct cytotoxic effects all tumor cells. According to this mechanism, complete and permanent cure would be obtained by antineoplastic agents that succeed in killing all cancer cells including cancer stem cells and micrometastases. ${ }^{1,2}$ In fact, cancer has long been conceived and treated as a cell-autonomous phenomenon, regardless of the immune system's contribution to the therapeutic response. Recently, we have challenged this idea by showing that, at least in the case of anthracyclin-mediated chemotherapy, the antitumor immune response plays a major role in therapeutic success. Thus, immunocompetent mice bearing CT26 colon carcinomas or MCA205 fibrosarcomas can be cured by intratumoral injection of anthracyclins, whereas immunodeficient mice lacking $\mathrm{T}$ cells only exhibit partial responses with a delay in tumor growth. $^{3-5}$ Detailed molecular studies revealed that anthracyclins have the peculiar capacity of inducing immunogenic cell death. In contrast, many other cytotoxic agents including agents that damage nuclear DNA (such as etoposide and mitomycin C), mitochondria, the endoplasmic reticulum or lysosomes fail to induce immunogenic cell

Figure 1 Early CRT exposure is required for the immunogenic effect of $\gamma$-irradiation or UVC light exposure. (a, $\mathbf{b})$ Kinetics of PS exposure and cell death induced by $\gamma$-irradiation (a) or UVC light (b). CT26 colon cancer cells cultured in RPMI 1640 medium supplemented with $10 \%$ FCS, penicillin, streptomycin, $1 \mathrm{mM}$ pyruvate and $10 \mathrm{mM}$ HEPES and treated by $\gamma$-irradiation (75 Gy) or UVC light $\left(100 \mathrm{~J} / \mathrm{cm}^{2}\right)$. After the indicated time period, cells were trypsinized and stained with FITC-labelled annexin V and propidium iodide following standard protocols, ${ }^{21}$ and subjected to cytofluorometric analyses. Numbers in each quadrant refer to the percentage of cells $(X \pm S . E . M$. of triplicates). (c, d) Immunofluorescence detection of CRT exposure on the cell surface in response to $\gamma$-irradiation (c) or UVC light (d). Cells treated as above were stained for the detection of surface CRT as described ${ }^{4} 1 \mathrm{~h}$ after treatment. Representative cells are shown. (e, f) Kinetics of CRT exposure determined by FACS analysis after $\gamma$-irradiation (e) or UVC light (f). Cells treated as in panels $\mathbf{a}$ and $\mathbf{b}$ were trypsinized and stained for the detection of CRT on the cell surface while gating on the viable population and excluding dead cells staining with propidium iodide. The CRT-specific staining profiles, as obtained for each time point post-treatment, are compared with those of untreated cells. (g, h) Manipulation of CRT exposure by an siRNA and adsorption of recombinant CRT protein. Cells were transfected with a control siRNA or a CRT-specific siRNA heteroduplex (sense strand: $5^{\prime}$-rCrCrGrCUrGrGrGUrCrGrArAUrCrRrArATT-3'). Thirty-six hours later, the cells were subjected to $\gamma$-irradiation (g) or UVC light (h), cultured for $4 \mathrm{~h}$, optionally treated with recombinant CRT protein $\left(3 \mu \mathrm{g} / 10^{6}\right.$ cells in PBS on ice for 30 min, followed by three washes) and subjected to immunofluorescence staining of CRT as above. (i, j) Requirement of CRT exposure for the immunogenic effect of ionizing irradiation. CT26 colon cancer cells were transfected with the indicated siRNAs, $\gamma$-irradiation (i), UV light (j) and/or recombinant CRT (as in $\mathbf{g}$ and $\mathbf{h}$ ) and then injected subcutaneously $\left(3 \times 10^{6}\right.$ cells) into the left flank of BALB/c mice. One week after this vaccination, the mice were challenged with live tumor cells in the opposite flank (day 0 ) and the frequency of tumor-free animals was monitored (mean \pm S.E.M.); $n$ represents the absolute number of mice enrolled in each cohort. ${ }^{*} P<0.001$ (Student's $t$-test) 
death. $^{4,6}$ Thus, etoposide and mitomycin $\mathrm{C}$ exhibited an identical therapeutic (in) efficacy in normal and athymic mice. $^{3}$ The molecular difference between immunogenic and non-immunogenic chemotherapies turned out to reside in the fact that immunogenic cell death is accompanied by the early, pre-apopotic exposure of calreticulin (CRT) on the surface of the plasma membrane. This early CRT exposure allows tumor cells to be efficiently engulfed by dendritic cells (DC), ${ }^{4,5}$ thereby setting the stage for efficient presentation of cancerspecific antigen to cytotoxic T lymphocytes. ${ }^{7-11}$ a

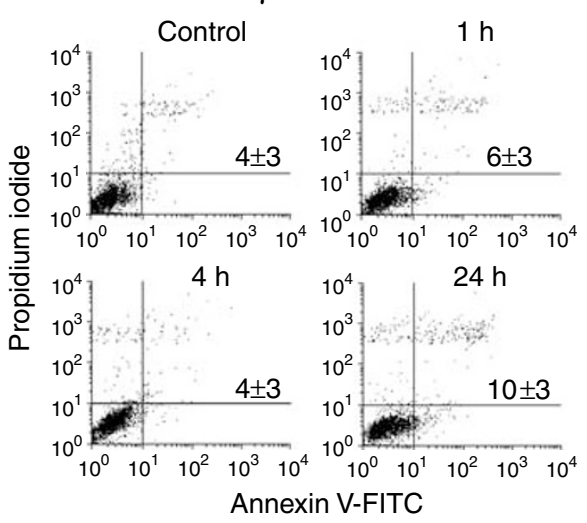

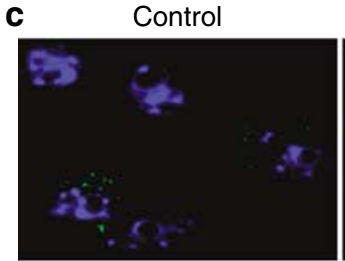

- Hoechst 33342

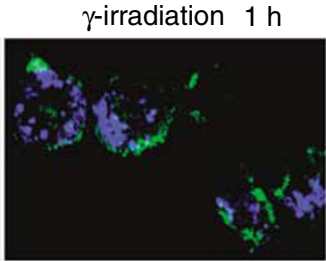

- Calreticulin e

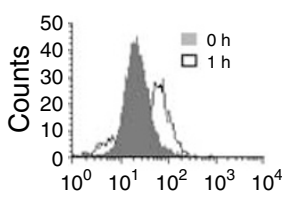

$\gamma$-irradiation

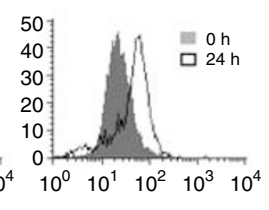

Anti-CRT-FITC
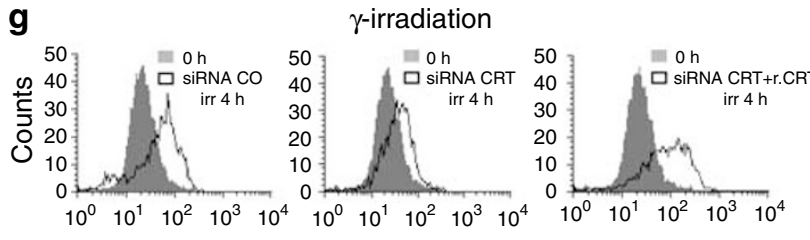

Anti-CRT-FITC

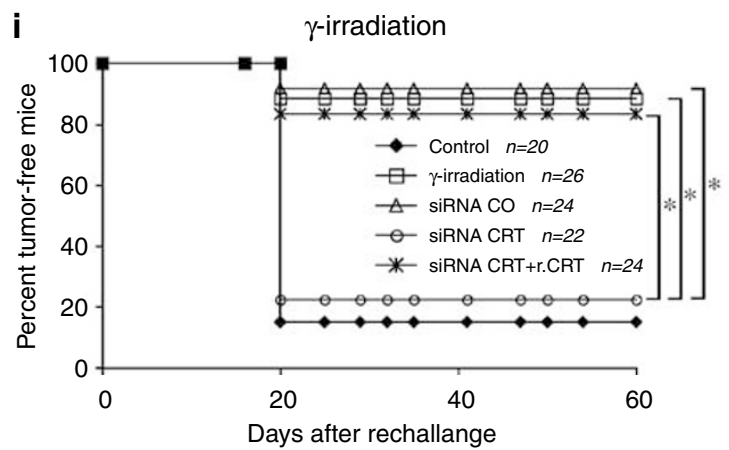

b

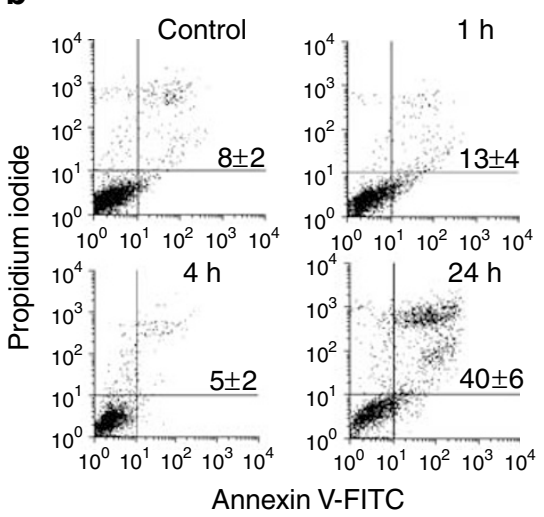

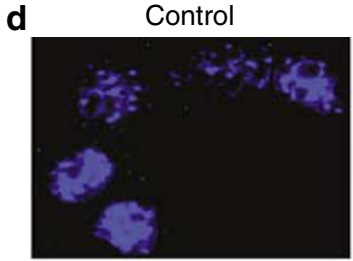

- Hoechst 33342

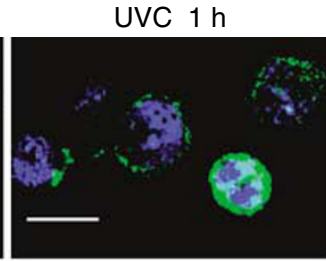

- Calreticulin $\mathbf{f}$

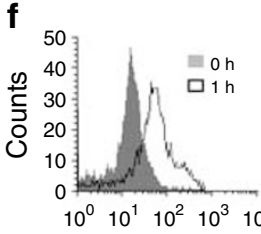

UVC

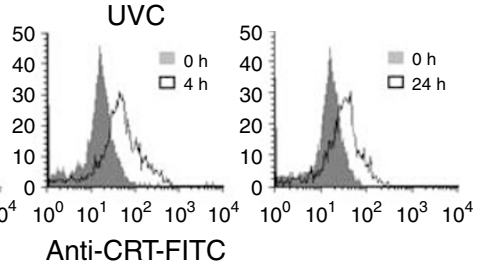

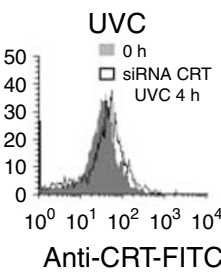

UVC

j

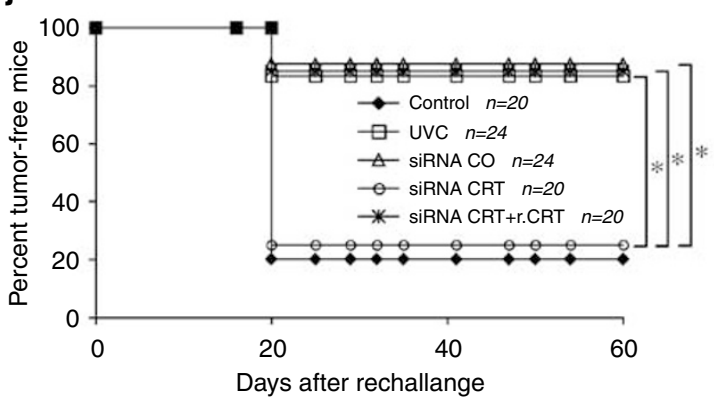


When screening for lethal stimuli that would yield immunogenic cell death, we found that $\gamma$-irradiated CT26 cells (75 Gy, followed by 4 or $24 \mathrm{~h}$ culture) were not able to form tumors when inoculated $\left(3 \times 10^{6}\right.$ cells subcutaneously) into male $\mathrm{BALB} / \mathrm{c}$ mice. In contrast, such irradiated cells were highly efficient $(90 \%)$ in preventing the growth of live CT26 cells $\left(0.5 \times 10^{6}\right.$ cells $)$ injected 7 days later into the opposite flank (see below). ${ }^{4}$ The percentage of the cells that exhibited phosphatidylserine (PS) on the cell surface or had lost their viability (Figure 1a) was near to $4 \%$ after $4 \mathrm{~h}$ of irradiation and $10 \%$ after $24 \mathrm{~h}$ of irradiation. Prompted by this observation and an ample literature suggesting that ultraviolet C (UVC) light can induce immunogenic cell death, ${ }^{12-14}$ we decided to study the kinetics of CRT exposure after lethal $\gamma$-irradiation or UVC light exposure. While both $\gamma$-irradiation or UVC light exposure had no or little effect on PS exposure at 1 or $4 \mathrm{~h}$ posttreatment, respectively (Figures $1 \mathrm{a}$ and $\mathrm{b}$ ), both resulted in a significant $(P<0.01$, Student's $t$-test) increase in CRT exposure as early as $1 \mathrm{~h}$ after treatment, as detectable by immunofluorescence staining and microscopic (Figures 1c and d) or cytofluorometric analyses (Figures 1e and f). Thus, CRT exposure induced by ionizing irradiation occurs at the pre-apoptotic stage, in viable cells that lack PS exposure (Figures 1a and b), as well as nuclear characteristics of apoptosis ${ }^{15}$ (Figures 1c and d).

Next, we determined the impact of CRT exposure on the immunogenicity of tumor cells treated by $\gamma$-irradiation or UVC light. To this end, CT26 cells were treated with a small interfering RNA (siRNA) specific for CRT or a control siRNA. Knockdown of CRT resulted in the absence of CRT exposure after $\gamma$-irradiation or UVC light exposure, as determined $4 \mathrm{~h}$ after the apoptotic insult. This defective CRT exposure could be re-established by adsorbing recombinant $C R T^{4,5,16,17}$ to the cell surface (Figures $1 \mathrm{~g}$ and $\mathrm{h}$ ). Then, we determined the capacity of $\gamma$-irradiated or UVC-exposed cells to induce a productive antitumor immune response. The cells were washed with PBS and were then injected subcutaneously into histocompatible immunocompetent hosts. One week later, the mice were challenged by subcutaneous injection of live, untreated CT26 cells into the contralateral flank. Both $\gamma$-irradiated and UVC-exposed cells exposing CRT were strong anticancer vaccines. Depletion of CRT with the siRNA strongly reduced the immunogenicity of $\gamma$-irradiation or UVC light exposure, and this effect could be fully overcome by adsorption of CRT to the tumor cell surface (Figures 1g-j). These results formally prove that CRT exposure is critical for the immunogenicity of cell death elicited by ionizing radiation.

Beyond the local and direct effects of $\gamma$-irradiation on the tumor itself and its stroma, there are a few indications in the literature that anticancer radiotherapy is more efficient in immunocompetent than in immunodeficient mice. ${ }^{18,19}$ In view of our findings, it will be interesting to investigate the contribution of CRT (and that of the molecular machinery leading to its translocation to the cell surface) to the success of radiotherapy. UVC exposure causes severe sunburn with a rapid inflammatory response. ${ }^{20}$ It will be important to study whether CRT exposure on cells of the basal keratinocyte layer or of the dermis may contribute to the inflammatory reaction and/or the phagocytic removal of damaged cells. Thus, the data presented in this letter to the editor have direct clinical and pathophysiological implications.

Another interesting question concerns the signal transduction pathway leading to CRT exposure. What are the mechanisms through which diverse stimuli such as ionizing irradiation and anthracyclins stimulate rapid CRT exposure, while many other apoptotic insults fail to elicit this reaction? We anticipate that responding to this question will allow us to predict which anticancer therapies may elicit an immune response against residual tumor cells, thereby improving the chances of definitive cure.

Acknowledgements. GK was supported by Ligue Nationale contre le cancer (Equipe labellisée), European Community (Active p53, RIGHT, Trans-Death, ChemoRes), Agence National pour la Recherche (ANR), Institut National contre le Cancer (INCa) and Cancéropôle lle-de-France. MO and AT receive fellowships from Fondation pour la Recherche Médicale.

M Obeid ${ }^{1,2,3}$, T Panaretakis ${ }^{1,2,3}, N$ Joza $^{1,2,3}, R$ Tufi $^{1,2,3}$, A Tesniere ${ }^{1,2,3}, P$ van Endert ${ }^{4,5}$, L Zitvogel $^{\star, 2,3,6,7}$ and G Kroemer Kr, 1,3,7 $^{\text {A }}$

1 INSERM, U848, F-94805 Villejuif, France

2 Institut Gustave Roussy, F-94805 Villejuif, France;

${ }^{3}$ Faculté Paris Sud-Université Paris 11, F-94805 Villejuif, France;

4 INSERM, U580, F-75015 Paris, France;

${ }^{5}$ Université Paris Descartes, Faculté de Médecine René Descartes, F-75015 Paris, France and

6 INSERM, U805, Institut Gustave Roussy, F-94805 Villejuif, France

7 LZ and GK share senior co-authorship.

* Corresponding authors: G Kroemer, Unit 848, INSERM, Institut Gustave Roussy, Pavillon de Recherche 1, 39, rue Camille Desmoulins, F-94805 Villejuif, France. Tel: +33-1-42-11-60 46; Fax: + 33-1-42 1160 47; E-mail: kroemer@igr.fr or

L Zitvogel, U805 and CIC BT507 INSERM, Institut Gustave Roussy, 39 rue Camille Desmoulins, F-94805 Villejuif, France. Tel: + 33-1-42 1150 41;

Fax: + 33-1-42 1160 94; E-mail: zitvogel@igr.fr

1. Kamb A, Wee S, Lengauer C. Nat Rev Drug Discov 2007; 6: 115-120.

2. Dancey JE, Chen HX. Nat Rev Drug Discov 2006; 5: 649-659.

3. Casares N et al. Exp Med 2005; 202: 1691-1701.

4. Obeid M et al. Nat Med 2007; 13: 54-61.

5. Obeid $\mathrm{M}$ et al. Immunol Rev (In press).

6. Galluzzi L et al. Cell Death Differ 2007; 14: 1237-1243.

7. Lake RA, van der Most RG. N Engl J Med 2006; 354: 2503-2504.

8. Storkus WJ, Falo Jr LD. Nat Med 2007; 13: 28-30.

9. Waterhouse NJ, Pinkoski MJ. Apoptosis 2007; 12: 631-634.

10. Clarke C, Smyth MJ. Nat Biotechnol 2007; 25: 192-193.

11. Blachere NE, Darnell RB, Albert ML. PLoS Biol 2005; 3: e185.

12. Ronchetti A et al. J Immunol 1999; 163: 130-136.

13. Kotera Y, Shimizu K, Mule JJ. Cancer Res 2001; 61: 8105-8109.

14. Zitvogel $L$ et al. Adv Immunol 2004; 84: 131-179.

15. Kroemer G et al. Cell Death Differ 2005; 12 (Suppl 2): 1463-1467.

16. Gardai SJ et al. Cell 2005; 123: 321-334.

17. Culina S, Lauvau G, Gubler B, van Endert PM. J Biol Chem 2004; 279: 54210-54215.

18. Chakravarty PK et al. Cancer Res 1999; 59: 6028-6032.

19. Meng $Y$ et al. Int J Cancer 2005; 116: 992-997.

20. Candi E, Schmidt R, Melino G. Nat Rev Mol Cell Biol 2005; 6: 328-340.

21. Castedo M et al. J Immunol Methods 2002; 265: 39-47. 